\title{
Lack of Coordination between Health Care and Social Care in Multi-Professional Teamwork - the Obstacle for Coherent Care of Older People Suffering from Multi-Morbidity
}

\author{
Ulla Melin Emilsson ${ }^{1}$ (D) Anna-Lena Strid ${ }^{1} \cdot$ Maria Söderberg $^{1}$ (D)
}

Received: 1 April 2020 / Accepted: 26 August 2020 / Published online: 11 September 2020

(C) The Author(s) 2020

\begin{abstract}
The lack of a cohesive health and social care is a well-known problem of significance for ageing people in general and frail older people in particular. Responsibility for organising and conducting social care and healthcare for the elderly rests on different principals in different countries but difficulties with organisational coordination and collaboration between professions and authorities in social care and healthcare is an extensive concern worldwide. Regardless of the distribution of responsibilities, collaboration and coordination structures are complex and often lead to problems. However, the gap in the coordination between different organisations and the collaboration between professions, implying that frail older people with major care needs still living in their own homes are pinched, has received hardly any recognition. By closely following an implementation project focused on teamwork in order to improve collaboration and coordination between social care and healthcare, the purpose of this article is to fill this gap with the help of an example from Sweden. Data consisted of event diaries, observations, focus groups, structured questionnaires and interviews. Findings showed that multi-professional teams certainly were established, but did not work or last. Among the obstacles found the most prominent features were the various professions' own organisations, territorial thinking and rivalries. The whole idea of the initiative to achieve a cohesive healthcare and social care for ageing frail older people fell through. By letting this happen, not only did the project hinder the development of better practice in serving older adults, but also cemented the problematic structures it was intended to dissolve.
\end{abstract}

Keywords Collaboration, coordination, social care $\cdot$ Healthcare $\cdot$ Teamwork older people $\cdot$ Multimorbidity

Ulla Melin Emilsson

ulla.melinemilsson@soch.lu.se

1 School of Social Work, Lund University, Lund, Sweden 


\section{Introduction}

Responsibility for organising and conducting social care and healthcare for the elderly rests on different principals in different countries (de Carvalho et al. 2017). The commitment covers medical, social and financial responsibility as well as the families' part. The organisation looks different in various countries where the form and degree of welfare system has a significant role that implies dissimilar forms of individual responsibility and private care providers. The orientation towards social or medical orientation as well as the responsibilities of families differs considerably in some European countries where France has a more medically oriented care and where the family has the ultimate responsibility while a country like Portugal's system is based on a more socially built care where society takes on greater responsibility (Melin Emilsson 2009). In countries such as the United Kingdom, Australia and Canada with more similar welfare regimes as the Nordic model in which Sweden is included, the orientation is more focused on coordination between the various principals on responsibility for social care and healthcare (Hébert, et al. 2010; Glendinning 2003; Venturato et al. 2019). Regardless of the distribution of responsibilities between various authorities, collaboration and coordination structures are complex and often lead to problems. Thus difficulties with coordination between healthcare and social care are neither a new nor unknown phenomenon and reported from various countries (Briggs and Araujo de Carvalho 2018; Cameron et al. 2014; Valaitis et al. 2020). However, the gap in the coordination between different organisations and the collaboration between professions, implying that frail older people with major care needs still living in their own homes are pinched, has received hardly any recognition which also have been highlighted in countries such as the UK (Lymbery 2006; Phillips and Waterson 2002; Valaitis et al. 2020). By closely following the implementation of teamwork in order to improve collaboration and coordination between social care and healthcare, the intention of this article is to fill this vacuum with the help of an example from Sweden.

The concept of "collaboration" in itself is multifaceted and includes different dimensions from the occasional recurring contacts, regular collaboration and appropriate integration, to close partnership. However, opinions on how collaboration best benefits the recipients are many and often different. That collaboration is essential both within and between healthcare and social care is neither new nor unique to Sweden and discussed already 1906 in the US (see MHG Social Work 2011). The lack of overall responsibility for the patient is a problem (National Board of Health 2011) and people most in need are the most affected. Problems with coordination between different principals are also reported from other countries such as England by Thompson and Postle (2007) and Canada by Valaitis et al. (2020).

Multi-professional teams are often seen as the obvious solution to the lack of collaboration (Berlin \& Carlström 2009; Leipzig et al. 2002; Tanaka 2003; Thylefors et al. 2005; Vyt 2008). Perspectives and working methods vary but in human service organisations, the approach exists primarily in the healthcare domains (Blomqvist 2009; Lundgren and Molander 2008). Internationally, research on multi-professional teamwork is most frequent in studies on professions' or organisations' theoretical approaches and results often indicate inter-professional difficulties (Cott 1998; Houssami and Sainsbury 2006; Jünger et al. 2007). With the exception of care planning and hospital discharge (Efraimsson et al. 2006; Reed and Stanley 2003), organisational 
teamwork occurs only exceptionally between health- and social based care of older people but examples are reported by Melin Emilsson (2011) and Taylor (2012).

In the intervention study followed one of the motives was to identify complex care needs among frail older people. The term "multi-ill" is often used for frail older people (Fratiglioni et al. 2010), even if there is no uniform definition. In an epidemiologic and public health perspective focused on identifying presence of risks and multi-morbidity the expression "multiple comorbid diseases in the same individual" is frequent (ibid). In this article, the expressions older people suffering from multi-morbidity or frail older people are selected. The ambition of the project was that the multi-professional teams established were supposed to continue functioning also after the end of the project period. This would lead to resource savings and a more cohesive care, and thereby a better understanding for the concept of ageing, with its consequences and prerequisites.

\section{Implementation of Multi-Professional Interdisciplinary Teams}

Over the past 20 years, the average life expectancy in Sweden for men has increased by 4 yrs to be 80.8 in 2018 and for women with 3 yrs to 84.3 (SCB, Statistics Sweden 2020). According to Statistics Sweden's population projection, the women who reach the age of 65 this year will on average have 23 years to live, while the men will have 21 years. This means that the number of older people is increasing at a rapid rate and in 2018 it was estimated that Sweden in 2028 will have 309,000 more people who are 65 years and older compared to today. As the ageing process in older age increases the risk of morbidity, this in turn implies that the need of a functioning health- and social care also will be growing. A coherent care is a prerequisite and already a problem with today's number of older people. This article focuses on the lack of coordination between healthcare and social care and the consequences it has particularly for an ever-growing group of ageing old people who still live in their own homes. And for various reasons the number of older people who stay in their homes at a high age is constantly rising. On the one hand, it is about lack of special housing, but also because of the fact that many people prefer to stay in their own homes. The importance of one's own home to well-being is reported both among younger elderly (Kylén et al. 2017) and from very old people (Dahlin et al. 2007). But, if the service does not work, the home becomes a health risk instead of a resource (Oswald et al. 2007). Above all debated in Sweden are the relations between the home care services and social care in special housing (Jönson 2004; Larsson 2004; Melin Emilsson 2005, 2009, 2014, Strid 2007, Szebehely 2003; Söderberg 2018, 2020; Söderberg et al. 2015; Thorslund 2002; Wikström 2005).

\section{Aim and Points of Departure}

This article is about a try-out to solve the problem by creating multi-professional interdisciplinary teams and contributes with knowledge intended to fill the gap that prevails both in the collaboration between social care and healthcare as well as knowledge about how this gap occurs. In spite of the fact that the main goal with the project under study was to improve the care for older people suffering from multi- 
morbidity, findings from an evaluation report published by the regional R\&D organisation (Wikström and Thulesius 2013) show that the elderly involved did not experience any changes. The purpose of this article is therefore to investigate what happened and try to understand what went wrong. It can be seen as a "case" or example of how a national initiative fails because of lack of cooperation between both organisations and professional groups which also occurs in an international context (Briggs and Araujo de Carvalho 2018; Cameron et al. 2014; Valaitis et al. 2020). Hasenfeld's (Hasenfeld et al. 1987; Hasenfeld 2010) theories on how human service organisations work provide a framework for the analysis together with theories about teamwork and Hudson's notions about professional identity and the impact of professional status. The data was collected by following an implementation project throughout the implementation from overall establishment with the employment of personnel to formation of teams. The interaction processes were studied in parallel both at a more general level and in more condensed form as the team participants did not only represent their professions but also their respective organisations.

The following research questions were formulated:

- How was the implementation of multi-professional teams organized?

- Which professions from the various principals were included?

- Why did the target of improving the care fell?

- What was the main problem? Teamwork, collaboration and coordination, or competition?

As expressed in the purpose of this article, the intention is to try to understand how it might turn out that the attempt failed. This is done by following and analysing what the different actors were doing in relation to each other and the task of creating teams to improve collaboration and coordination.

\section{Coordination and Collaboration between Organisations and Professions}

Coordination between various authorities has over the years come more into focus in Sweden. In 2011 the National Board of Health published a supervisory report on healthcare and social services in which they expressed sharp criticism of the lack of coordination both within the various organisations and between different authorities (National Board of Health 2011). The lack of coordination was one of the most central points in the work within health and social services. It is about interaction problems within organisations and between them; in different ways and to different degrees with obvious consequences for ageing people in general and older people suffering from multi-morbidity in particular. It turned out that many governments had established joint procedures for coordination in connection with discharge from hospital but the professionals did not always follow the procedures. It was also found that the care of older people was too general and rule-driven, which is interesting as the staff did not follow the rules. The report explicitly stated "Collaboration is a prerequisite for the individual to get the support that meets his or her needs. Thus it is also a necessary factor to achieve good quality", (National Board of Health 2011, p. 53). Despite the ambitions 
major deficiencies were found, which resulted in long wait for care for frail older people.

The same year SKL - the Swedish Association of Local Authorities and Regions, took a national initiative to support collaboration and 19 projects across the country received funding. By following one of those projects focused on older people suffering from multi-morbidity still living at home, the implementation of multi-professional teams between healthcare and social care organisations was studied. The coordination between different authorities studied through the collaboration between different professions is highlighted, and its impact on frail older people. Data consist of event diaries, observations, and focus groups.

The project followed received funding for 3 yrs to develop strategic and sustainable ways of coordination and collaboration to overcome regulatory- as well as professional boundaries. With the help of multi-professional teamwork as the main method, a new type of management was supposed to be implemented. The approach itself was neither new nor untested and findings from earlier studies demonstrated major difficulties in need to be solved (Blomqvist 2009; Schofield and Amodeo 1999). But what motivated this particular initiative was that it was introduced as a new design with teams composed not only by different professionals but also by representatives of various occupations from both municipalities and county councils. A central point was that the multi-professional teams were expected to improve the coordination of care for frail older people still living in their ordinary homes and a better utilization of resources.

The terms "coordination" and "collaboration" are closely related in the meaning that organisations and people are planning and working together. In this article coordination means decisions, negotiations and strategies, politically or administratively at a national or county based level. Collaboration is the term used meaning direct interaction between people. It may be professionals employed at the same workplace but also various professionals from workplaces in direct physical meetings as might be the case in multi-professional teamwork.

\section{Theoretical Frameworks}

In this type of project, which implies following the implementation of another project, the approaches to some extent are woven together. To illustrate the complexity of the structural societal context, a matrix of Corbin \& Strauss (1996, p.141) is used as a frame where the model of teamwork (Fig. 2) and the model that shows the course of events (Fig. 3) is placed into the various levels. Corbin \& Strauss discuss what happens in the interaction between people, how they actually act in a certain context on one level, horizontally as well as vertically and how they affect and are affected by what happens in other parts of the structures. They illustrate all levels where the outermost circle is on the international level and the innermost focuses on the individual's behaviour (ibid. p. 141). Thus, when applying this structure on the project under study the frail older person is placed in the very centre of the circle. In between the levels there are actions among groups; institutions and organisations. Teamwork and course of events are placed here but also in the societal level which comes next. Closest to the international component is the national context. Corbin \& Strauss emphasize the importance of using theoretical assumptions that are based on the same level as the 
phenomenon studied. In this study, initially the empirical data was collected at all levels with the exception of the international. In this article the main focus is on the interaction between professional groups, spanned over organisational boundaries.

In this work primarily theories on teamwork (Berlin \& Carlström 2009), and on human service organisations (Hasenfeld et al. 1987; Huby and Rees 2005) are applied together with Hudson's (2002) ideas about professional rivalries. When it comes to the analyses of the teamwork, a model designed by Berlin \& Carlström (2009) is used. This model focuses on how teams as a whole are acting from a sequential, parallel and synchronous working model (see Figs. 1 and 2).

By firstly applying this model, a comprehensive structure of how the various teams' work is crystallized. The analysis is then deepened with another model that is based on the different professions and their actions from various perspectives focused on role taking, leadership and allocation of tasks which ends up into the three general types of teamwork; multi-professional, inter-professional and trans-professional (Thylefors et al. 2005).

Hasenfeld (Hasenfeld et al. 1987; Hasenfeld 2010) is used in an attempt to understand how and why people in the organisations act as they do. He argues that organisations working on the people as "raw materials" are particular complex and difficult to study and that in some sense they do what they want and always have done. Hasenfeld discusses three different assumptions about how organisations work. The first is about the relationship between organisations and their environment and

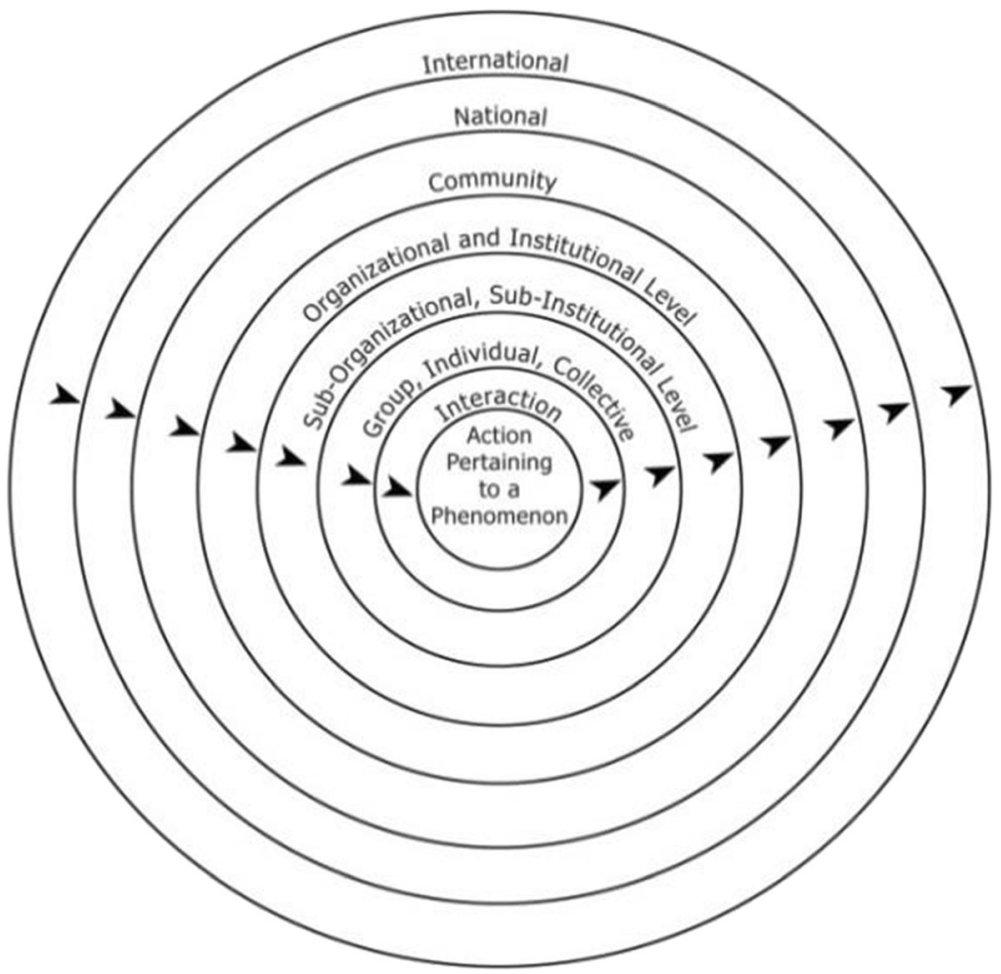

Fig. 1 Matrix by Corbin \& Strauss (1996, p.141) 


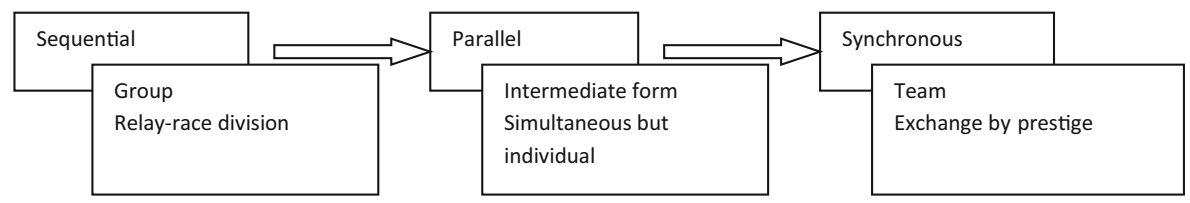

Fig. 2 From sequential to synchronous team (Berlin and Carlström 2008 p 571)

addresses the issue of the degree of openness to the environment and its importance to the internal organisation and structure. The second focuses on the degree of control within the organisation and how well it can control its own destiny. And the third assumption takes a view of organisations as purposefully designed systems; as an adaptive system or a system whose attributes are primarily determined by forces beyond its control (a a p. 24). Huby and Rees (2005) argue for the importance of both a horizontal and vertical integration. They mean that collaboration between professionals at similar levels in various organisations is essential, but equally central is that this collaboration is supported by a vertical integration. But different organisational structures have different strategies at different levels, which further demonstrate the complexity (see Axelsson and Bihari Axelsson 2006). A connection is also made to Hudson (2002) and his discussion of professional identity and professional status in relation to internal professional rivalries as barriers to collaboration and teamwork.

The concept implementation will not be discussed more in this article but it is worth noting that there are no single universal definition accepted and research on implementation come from different scientific traditions.

\section{Methods and Material}

The object under study consisted of a three-year collaboration project, which was supposed to be implemented across various organisational boundaries within an entire county. The reason why this particular project was chosen was mainly that it was about collaboration between social care and healthcare which was an area earlier studied by the researchers in a European context (Melin Emilsson 2009). In the national initiative taken by SKL - the Swedish Association of Local Authorities and Regions, with the aim of improving both social care and healthcare of frail older people still living at home, the other 18 projects had completely different approaches, still with the same objective. Another reason for choosing this project was that it would be implemented in the county where the university is located and with previously established contacts it would provide access to the research field. Geographic proximity was also a prerequisite as a variety of groups would be followed for a long time. Furthermore there is another not insignificant factor, namely that one of the major prestigious research funders in Sweden, Forte - Swedish Research Council for Health, Working Life and Welfare (earlier FAS) also considered it an urgent project and fully financed the study over the 3 yrs (Dnr 2011-0524).

The data used in this article is completely qualitatively based without the possibility of statistical calculations. This combined with the fact that none of the other national projects had this focus, meant that comparisons with other regions or projects could not be made either. Partners in the collaboration project were emergency care, primary care 
and local health and social care. The first author of this article followed the project and had access to all groups and meetings from the planning stage throughout implementation. In this text the teams' compositions and work are focused but to give an idea of the collaboration project as a whole and how it was followed, a brief presentation of the data collection is introduced. The teams consisted of physicians, nurses, paramedics, care managers and nursing staff from the county and nine geographically distributed municipalities.

In total, the empirical data consisted of:

- Focus group interviews with the 11 constellations of groups - at the beginning and end of the project period

- Observations of working meetings at least two times per team

- Focus group interviews with the leaders of the 9 teams - the beginning and end of the project period

- Individual semi-structured interviews with the project managers - in the beginning and end of the period

- Event diaries from managers at different organisational level in the county and the 8 municipalities involved

- Individual semi-structured interviews with 16 of the older people who received healthcare in the context of the multi-professional teams work

- All documentation related to the collaboration project and its implementation

- Structured questionnaires before and after the intervention (43 frail older people in ordinary living, 28 the second time)

The interviews taken into consideration in this article, both individually based and in the form of focus groups, were aimed at providing information about the teams' composition, how they were working and the participants' own experiences of the work and the collaboration project (Fontana and Frey 2005; Merton et al. 1956). The observations were meant to enable researchers' pictures of what happened in order to learn about how collaboration between healthcare- and social service professions can be manifested in a coordinated multi-professional team based context, spanned over organisational boundaries.

The research project in its entirety was approved by the Regional Ethical Committee in Linköping (Dnr 2011/258-31). Regarding ethical considerations it can be mentioned that all of the older people who participated and all staff included received information letters and all assigned written informed consents. The possibility to cancel the participation at any time was specifically highlighted in all the letters.

\section{Findings and Analyses}

This article reports the implementation of multi-professional teams through the course of events and how the teams were formed. The approach chosen is to describe the process by going through this course of events. This way to study and describe in detail the different steps that were taken in the project, gives the opportunity to both bring out what was actually going on during the implementation and further what it resulted in. Through this description step by step it becomes clear who did what and when. If only 
one or more occasions are struck, every decision and action seems logical in its context. But in view of the whole and over time, another reality becomes apparent. This shows how social care is systematically outsourced by healthcare and this is done by the various professions competing with each other.

\section{The Course of Events - Who Does What and when}

The purpose of the whole collaboration project was to improve the care for older people suffering from multi-morbidity still living in their ordinary homes. On a national level The Swedish Association of Local Authorities and Regions was commissioned to organize funding for the country's county councils and municipalities to organize collaboration projects in order to improve the care for frail older people still living at home and in need of both health- and social care. With inspiration from the Matrix by Corbin and Strauss (1996), one can say that the collaboration project moved from the national level in the matrix as the whole implementation project was initiated and funded by a national authority and all the way to the individual level and vice versa. What is then happening at the various levels depends on and influences events and actions on the other levels in a complex and almost incalculable way. What the two project leaders do and say has significance and meaning for what the management team is doing in relation to the eight teams in the municipalities and so on as illustrated in Fig. 3.

What happened within and between the healthcare and social care organisations in the collaboration project is analysed in line with Hasenfeld's (2010) thinking. He believes that within so-called human service organisations the organisational procedures live its' own life and those processes are difficult to catch. What the different

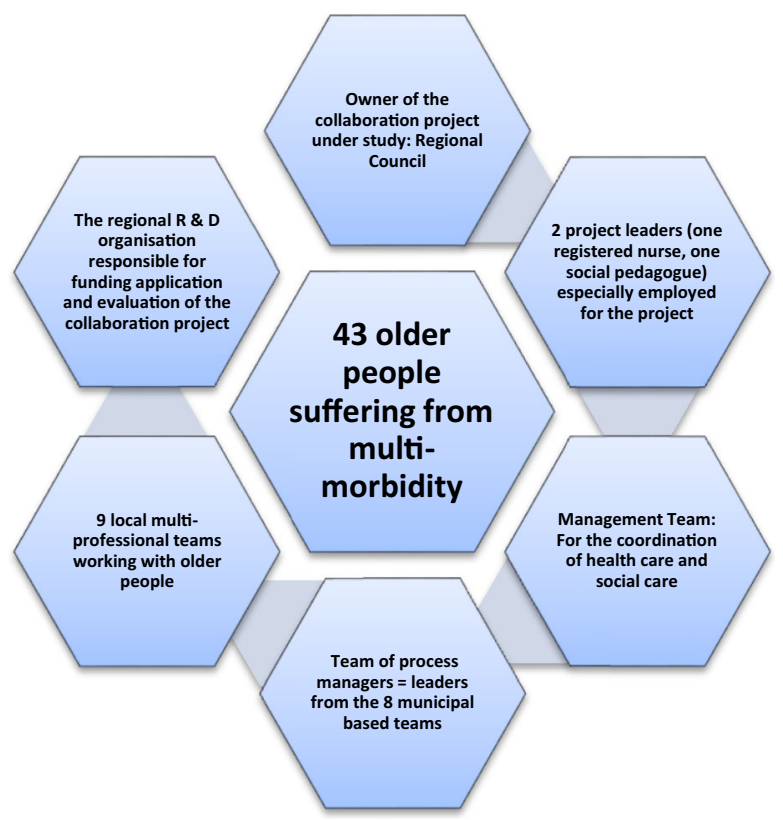

Fig. 3 The course of events; starting clockwise at the top 
actors do and why, which in turn has consequences for the others in the organisation is difficult to capture and fully in line with Hasenfeld's thoughts that people as raw material do what they want and what they always have done. It is however possible to give a description of the various teams that gradually were established in order to improve the care through collaboration. In Fig. 3 the course of events are described from the point when the owners of the project - ultimately responsible - begin by recruiting two project leaders until the date when the project was supposed to be evaluated by the regional R \& D organisation. Before the local multi-professional teams eventually were formed, no less than 11 other constellations of groups were organised.

Starting with those responsible and then follow the events through the groupings created, the complex processes that took place are revealed. By reporting what was planned and what was actually carried through expose what happened and what created the foundation of the collaboration project. How the Regional Council which was composed of senior officials from both the county and the municipalities took the decision to recruit the two project leaders is not clear from any document but could be interpreted using Hasenfeld's way of thinking that they did as they always used to do. In a certain sense it was something that just happened without any reflection on what consequences it could possibly have for the frail older people in the project. One of those who had been involved in formulating the project idea expressed astonishment not having been consulted. It can be interpreted as a non-transparent style of leadership in a top-down managed organisation with little influence from those working in the activities, which consequently influences the prerequisites for a cohesive health- and social care for frail older people.

\section{Two Project Leaders from Healthcare}

From the very beginning of the collaboration project the two project leaders were employed at $50 \%$ by the County Council. In order to strengthen the multiprofessional character of the project and according to the original project plan, one of them would come from the healthcare and one from the social care sector. A nurse was recruited from the healthcare sector but the attempt to find anybody from the social care failed and the second hired was a social pedagogue with a healthcare background. Why it failed it to find someone from social care was impossible to get a sure picture of, but a bold interpretation may be that they did what they did in order to make sure that it would be as they wished. Thus, there was no clear representation from the area of social care to manage the project financed by the Swedish Association of Local Authorities and Regions. They should have suggested plans for information and communication and carry it through in the eight municipalities. Among their tasks was also to monitor the budget as well as subsequently follow up and report the economic outcomes to the team of project managers (see below). The project leaders considered themselves to be the link keeping the project together. When it comes to how they carried out the information task there were many critical comments from project fellows in the municipalities. They argued that the information they received was scarce and sometimes directly misleading with the effect that they did not know what to do. 


\section{A Team of Project Managers}

The project management team consisted of 12 people who met once a month. Four of them came from healthcare, the majority were doctors, four were managers from different municipalities, and one was a leader from the Regional Council. This management team also included the two project leaders. Referring to the professions and organisational affiliation of this group it can be stated that only the four managers from the municipalities were representing the social care sector. Furthermore changes in the composition occurred during the project implying that the representation of healthcare was expanded. Already in the group that would lead the collaboration project there was a strong imbalance between the two areas of health- and social care. A policy document was formulated for the implementation of the project. However it was perceived as vague and confusing in the municipalities. One of the participants from the multiprofessional teams said: "It took a long time before I even realized what it all was." Another said: "I do not think the project leaders themselves know what they mean". But even for the two project leaders it was difficult to grasp what to do and how. Overall, the project was perceived as strongly directed from the top, and many project managers expressed that they felt that they had no influence at all.

\section{A Team of Process Managers}

In order to ensure continuity in the project's implementation, a so-called local process manager was appointed to take responsibility for and follow the implementation process in each municipality. This meant that the process managers in turn were meant to be the contact person with the team of project managers and they would have been selected by the local multi-professional teams' participants. This plan was transformed in a process hard to catch (cf. Hasenfeld 2010). Partly it is about different organisations but with the same phenomenon. In Hasenfeld's terms, these organisations could be regarded as the type of system that was controlled by forces beyond their control. The formed groups could not even agree on choosing a local process manager. Instead the project leaders recruited process managers from each municipality that together with the project leaders would work out the conditions for the local teams. This can be interpreted as another step in the already top-heavy way of implementing the project. Nine process managers participated in the project. As regards the professional background was distributed according to Table 1.

When looking at the composition of this group the impact from the healthcare sector becomes even stronger. In addition to the fact that the two project managers represent healthcare seven out of nine process managers come from the healthcare sector.

Table 1 Process managers' vocational background

\begin{tabular}{lr}
\hline Vocational background & 3 \\
\hline Occupational therapist & 2 \\
Physiotherapist & 2 \\
Registered nurse & 2 \\
Social care worker &
\end{tabular}




\section{Local Multi-Professional Teams}

The local multi-professional teams in the eight municipalities were, according to the original project idea, the units that would conduct the actual improvement of care for frail older people. Firstly they would identify older people in need of comprehensive health- and social care with the risk of being trapped in the organisational structure of health- and social sectors. Then they were supposed to use their multi-professional competences and skills to adjust the care and also contribute to a good environment for this group of older people. The composition of the nine teams changed during the project period. Therefore it is difficult to actually grasp how they were structured and also how they were working (cf. Hasenfeld 2010).

During the whole period of the collaboration project in all 69 professionals were engaged in the nine local teams according to the distribution in Table 2.

The teams had between five and 10 participants. The numbers varied over time and with that also the professional composition. This meant that it was very difficult to analyse the work by means of team related theories. Using a model by Berlin and Carlström (2008) illustrated in Fig. 3, the multi-professional teamwork under study best would fit into the sequential form of coordination which is characterized by a traditional step-by-step working process in which each participant waits for her or his turn to perform a specific task.

In terms of general types of teamwork discussed by Thylefors et al. (2005), namely multi-professional, inter-professional and trans-professional the work performed was closest to just the multi-professional model as the teams in fact consisted of various professions but without the multi-professional interaction.

Should this be the case, it means, that no actual coordination of the kind intended takes place and that still the frail older people are trapped between the healthcare and social care system. When listening to the communication during the observations this picture was confirmed and even strengthened. Rather than discuss how the different professional skills could complement each other, and what would be the best for the elderly, they tried to convince each other that their own way of working was the best. Expressions such as "we usually do like this and it usually works fine" were frequent, which is in line with Hudson's (2002) ideas about inter-professional rivalries.

In the local multi-professional teams one can conclude that among the total of 69 employees, only 10 came from the field of social care. And of those 10, only three were

Table 2 Professions represented in the local multi-professional teams

Profession

General practitioner (GP)

District nurse/Registered nurse

Physiotherapist

Occupational therapist

Assistant nurse 
graduated. The rivalry that occurred can not only be attributed to competition between professionals from healthcare and social care when only professionals from the healthcare participated. This in turn can hide an even more severe and problematic reality, namely a politically driven competition between the county council which is responsible for the healthcare and the municipalities with responsibility for social care. To draw conclusions about the competition at the organisational level is quite complicated and data in this study do not provide a basis for it as it is the individuals' actions and decisions which have been focused. What could possibly speak against a competitive relationship is that at the national level, which is partly politically driven, the responsibility for municipalities and county councils with regard to the care of the elderly is gathered under one nationwide organisation, namely the one that initiated this study namely SKL (now SKR) Swedish Association of Local Authorities and Regions.

\section{Concluding Reflections}

The main purpose of the collaboration project in its entirety was to improve the care for older people suffering from multi-morbidity still living in their ordinary homes. The improvement would be achieved by better coordination and collaboration between healthcare and social care. This would also prevent frail older people from getting trapped between the organisations. The working method that was planned to be used was multi-professional teams in all municipalities in the county. The fact that they did not achieve the goal of improving the care for the elderly in question is known on the basis of data and the evaluation published by the regional $\mathrm{R} \& \mathrm{D}$ organisation (Wikström and Thulesius 2013). But the findings also show that they neither managed to establish functional teams nor involve staff from both healthcare and social care which was what they actually got funding to do. Thus in its entirety, considering the whole collaboration project, the following conclusions can be drawn:

- The regional authority and the professionals failed in organizing effective multiprofessional teams

- The main goal of improving a cohesive health- and social care for ageing frail older people was not achieved

- The coordination and collaboration between healthcare and social care was not developed

- The inter-professional competition seemed stronger than the ability to collaborate

How to understand that? Despite all the good intentions, they did not manage to organise their work so that older people suffering from multi-morbidity would not continue to fall between the seats, in other words between the health- and social care organisations. And how can we understand that the social care is so poorly represented? Of the total of 92 direct actively involved only 16 professionals were linked to social care and of these, only three were trained social workers. Using Hudson's (2002) thoughts on the importance of professional status as obstacles in collaboration between professionals makes the process conceivably somewhat clearer. If you consider education level as a measure of professional status, it can be noted that of the 69 participants in the teams, 47 out of 59 from healthcare had a university degree while only three of 
the ten from social care (see Table 2). Although the data in total is relatively extensive with, among other things, documentation of all team meetings, it is not possible to determine how the basis for the decisions was made. However, it can be stated that the doctors who undoubtedly have the highest status were always those who led the meetings when they were present.

It is difficult to find a complete answer to why social care was underrepresented. However, what can be done is to summarize the process by which the different groups were created during the collaboration project. The whole process started back when the two project leaders, who both had a background in healthcare, were recruited. A reflective assumption that can be made is that perhaps already at this stage an organisational competition between the county council responsible for healthcare and the municipalities responsible for social care can be discerned. It can be interpreted as the governance from an organisational direction, namely healthcare, in that way was established. Thereafter, this continued because the more people with a healthcare orientation that became involved, the easier it was to recruit even more people with the same organisational orientation as shown in Table 3.

It is worth noting that 63 of the 76 professionals from healthcare had a university degree while there were only three of the 16 from the area of social care. If looking at it with a very positive and not overly critical attitude, one can imagine that it "just happened". The project leaders together with the project managers took out the people they knew, thinking that they had something to bring to the project in various respects. With a more critical approach, one can imagine that there is a more conscious way of acting, which severely stresses the shareholders, in this case the medical perspective, and thus creates the power to get more from that side. It is interesting as healthcare social workers with a holistic approach as the main hallmark are expected to be the professionals representing the contact between the healthcare and social care for older people. At the same time, in some sense the whole idea of the collaboration project, and the fact that health- and social care must work together to improve the care for frail older people, fell through. By letting this happen, not only did the project hinder the development of organisational coordination and collaboration between professionals, but also cemented the problematic structures it was intended to dissolve. This, in turn, will probably mean that the older people suffering from multi-morbidity in great need of both healthcare and social care will continue to fall between the chairs. To conclude it should be noted that this project did not contribute to better care and health for ageing older people still living in their homes.

Table 3 The participants' organisational affiliation

\begin{tabular}{llll}
\hline Category & Social care & Healthcare & Total \\
\hline Project leaders & $\mathbf{0}$ & $\mathbf{2}$ & $\mathbf{2}$ \\
Team of project managers & $\mathbf{4}$ & $\mathbf{8}$ & $\mathbf{1 2}$ \\
Team of process managers & $\mathbf{2}$ & $\mathbf{7}$ & $\mathbf{9}$ \\
Multi-professional teams & $\mathbf{1 0}$ & $\mathbf{5 9}$ & $\mathbf{6 9}$ \\
Total & $\mathbf{1 6}$ & $\mathbf{7 6}$ & $\mathbf{9 2}$ \\
\hline
\end{tabular}


Acknowledgements Open access funding provided by Lund University.

Open Access This article is licensed under a Creative Commons Attribution 4.0 International License, which permits use, sharing, adaptation, distribution and reproduction in any medium or format, as long as you give appropriate credit to the original author(s) and the source, provide a link to the Creative Commons licence, and indicate if changes were made. The images or other third party material in this article are included in the article's Creative Commons licence, unless indicated otherwise in a credit line to the material. If material is not included in the article's Creative Commons licence and your intended use is not permitted by statutory regulation or exceeds the permitted use, you will need to obtain permission directly from the copyright holder. To view a copy of this licence, visit http://creativecommons.org/licenses/by/4.0/.

\section{References}

Axelsson, R., \& Bihari Axelsson, S. (2006). Integration and collaboration in public health-a conceptual framework. The International Journal of Health Planning and Management, 21, 75-88.

Berlin, J.M., \& Carlström, E.D. (2009) "The 20-minute team - A critical case study from the emergency room". Journal of Evaluation in Clinical Practice, p. 1356-1294.

Blomqvist, S. (2009) Kompetensutnyttjande mångprofessionella psykiatriska team. Competence utilisation multi-professional psychiatric team. Linköping, (diss).

Briggs, A. M., \& Araujo de Carvalho, I. (2018). In PLoS ONE. 10/11/2018, Vol. 13 (10) p1-16.

Cameron, A., Lart, R., Bostock, L., \& Coomber, C. (2014). Factors that promote and hinder joint and integrated working between health and social care services: A review of research literature. Health \& Social Care in the Community, 22(3), 225-233.

Corbin, J., \& Strauss, A. (1996). Analytic ordering for theoretical purposes. Qualitative Inquiry, 2(2), 139150.

Cott, C. (1998). Structure and meaning in multidisciplinary teamwork. Sociology of Health \& Illness, 20(6), 848, 26p-873. https://doi.org/10.1111/1467-9566.00132.

Dahlin, S., Haak, M., Fänge, A., \& Iwarsson, S. (2007). The multiple meaning of home as experienced by very old Swedish people. Scandinavian Journal of Occupational Therapy, 14(1), 25-32.

de Carvalho, I. A., Epping-Jordan, J., Pot, A. M., Kelley, E., Toro, N., Thiyagarajan, J. A., John, R., \& Beard, J. R. (2017). Organizing integrated health-care services to meet older people's needs. Bulletin of the World Health Organization, 95, 756-763.

Efraimsson, S., Sandman, P.-O., Hydén, L.-C., \& Rasmussen, B. H. (2006). How to get one's voice heard? Journal of Advanced Nursing, 53(6), 646-655.

Fontana, A., \& Frey, J. H. (2005). Interviewing. The art of science. In N. K. Denzin \& Y. S. Lincoln (Eds.), Handbook of qualitative research, 361-376. London: Sage Publications.

Fratiglioni, L. Marengoni, A. Meinow, B. \& Karp, A. (2010) Multipla hälsoproblem bland personer over 60 år. En systematisk litteraturöversikt om förekomst, konsekvenser och vård. Multiple health problems among people over 60 years. A systematic review of prevalence, consequences, and treatment. SOU 2010:48. Stockholm: Regeringskansliet.

Glendinning, C. (2003). Breaking down barriers: Integrating health and care services for older people in England. Health Policy, 65, 139-151.

Hasenfeld, Y. (2010). Human services as complex organisations (2nd ed.). Los Angeles: Sage.

Hasenfeld, Y., Rafferty, J., \& Zald, M. N. (1987). The welfare state, citizenship, and bureaucratic encounters. Annual Review of Sociology, 13, 387-415.

Hébert, R., Raîche, M., Dubois, M.-F., Gueye, N. R., Dubuc, N., Tousignant, M., \& The PRISMA Group. (2010). Impact of PRISMA, a coordination-type integrated service delivery system for frail older people in Quebec (Canada): A quasi-experimental study. Journal of Gerontology: Social Sciences, 65B(1), 107118.

Houssami, N., \& Sainsbury, R. (2006). Breast Cancer: Multidisciplinary care and clinical outcomes. European Journal of Cancer, 42, 2480-2491.

Huby, G., \& Rees, G. (2005). The effectiveness of quality improvement tools: Joint working in integrated community teams. International Journal for Quality in Healthcare, 17, 53-58.

Hudson, B. (2002). Interprofessionality in health and social care: The Achilles' heel of partnership? Journal of Interprofessional Care, 16, 7-17. 
Jönson, H. (2004). Övergrepp mot äldre i två perspektiv. Elder abuse in two perspectives Socialvetenskaplig tidskrift, 11(3-4), 310-328.

Jünger, S., Pestinger, F., Elsner, F., Krumm, N., \& Radbruch, L. (2007). Criteria for successful multiprofessional cooperation in palliative care teams. Palliative Medicine, 21, 347-354.

Kylén, M., Schmidt, S. M., Iwarsson, S., Haak, M., \& Ekström, H. (2017). Perceived home is associated with psychological well-being in a cohort aged 67-70 years. Journal of Environmental Psychology, 51(2017), 239-247.

Larsson, K., (2004). According to Need? Institutionen för Socialt arbete, Stockholms universitet (diss).

Leipzig, R S, Hyer, K, Ek, K, Wallesntein, S, Vezina, M, Farichild, S, Kassel, CK, \& Howe, J (2002). "Attitudes Towards Working on Interdisciplinary Healthcare Teams: A Comparison by Discipline, JAGS, 1141-1158.

Lundgren, C \& Molander, C (2008) Teamarbete i medicinsk rehabilitering. Teamwork in medical rehabilitation. Liber, Stockholm.

Lymbery, M. (2006). United we stand? Partnership working in health and Social care and the role of Social Work in Services for Older People. British Journal of Social Work, 36, 1119-1134.

Melin Emilsson, U. (2005). Recognizing but not acknowledging: On using research information in social work with elderly people suffering from dementia. British Journal of Social Work, 34(8), 1393-1409.

Melin Emilsson, U. (2009). Healthcare, social care or both? A qualitative explorative study of different focuses in long-term care of older people in France, Portugal and Sweden. European Journal of Social Work, 12(4), 419-434.

Melin Emilsson, U. (2011). The role of Social Work in cross-professional teamwork - Examples from an older People's team in England. British Journal of Social Work, 29, 1-19.

Melin Emilsson, U (2014) "Socialt arbete och sjuka äldre", In Lalos, A. Blom, B. Morén, S. \& Olsson, M. (red) Socialt arbete i hälso- och sjukvård". Stockholm: Natur \& Kultur.

Merton, R.K., Fiske, M. \& Kendall, P. L., (1956).The focused Interview.2nd ed, New York: Free press.

MHG Social Work (2011) www.mghsocialwork.org/history.html (Retrieved Maj 2011) P. and Cameron, C., (2004). Does "care work" have a future? Socialv tidskrift, 11(3-4), 223-237.

National Board of Health (2011) Tillsynsrapport 2011. Hälso- och sjukvårdoch socialtjänst. www. socialstyrelsen.se. Accessed May 2011.

Oswald, F., Wahl, H. W., Schilling, O., Nygren, C., Fänge, A., Sixsmith, A., et al. (2007). Relationships between housing and healthy aging in very old age. Gerontologist, 47(1), 96-107.

Phillips, J., \& Waterson, J. (2002). Care management and social work: a case study of the role of social work in hospital discharge to residential or nursing home care. European Journal of Social Work, 5(2), 171186.

Reed, J., \& Stanley, D. (2003). Improving communication between hospitals and care homes: The development of a daily plan for older people. Health \& Social Care in the Community, 11(4), 356-363.

Schofield, R. R., \& Amodeo, M. (1999). Interdisciplinarity teams in healthcare and human services setting: Are they effective? National Association of Social Workers, 1999, 210-219.

Söderberg, M. (2018). A part of social work and apart from social work: Hospital nurses when older people consider relocation to a residential home. Nordic Social Work Research, 8(2), 146-157.

Söderberg, M. (2020) "Moral choices and responsibilities: The home-help service at the borderland of care management when older people consider relocation to a residential home". Ethics and Social Welfare, Accepted 28 May 2020. https://doi.org/10.1080/17496535.2020.1776749, 1, 15.

Söderberg, M., Ståhl, A., \& Melin Emilsson, U. (2015). How care managers handle the process when older people consider relocation to a residential home. British Journal of Social Work, 45 (8), 2423-2440.

Strid, A-L. (2007) Working in the presence of death - Routines and rituals in the Care for Older People. Lund University, School of Social Work, 2007:2 (diss, lic).

Statistics Sweden, SCB (2020). https:/www.scb.se/en/

Szebehely, M. (2003). Hemhjälp I Norden: Illustrationer och reflektioner. Home help in the Nordic countries: Illustrations and reflections. Lund: Studentlitteratur.

Tanaka, M. (2003). Multidisciplinary team approach for elderly patients. Geriatrics \& Gerontology International, 3, 69-72.

Taylor, B. (2012). Developing an integrated assessment tool for the health and social care of older people. British Journal of Social Work, 42(7), 1293-1314.

Thompson, C, \& Postle, K (2007) "The Use of Local Community Resources to Facilitate Preventive Approach to the Care of Older People: An Examination in a Rural Context", Practice, 19, 3, 211-226.

Thorslund, M., (2002). Dagens och morgondagens vård och omsorg: Om gapet mellan behov och resurser. Today's and tomorrow's healthcare: If the gap between needs and resources I Andersson, L., red. Socialgerontologi 231-251. Lund: Studentlitteratur. 
Thylefors, I., Persson, O., \& Hellström, D. (2005). Team types, perceived efficiency and team climate in Swedish cross-professional teamwork. Journal of Interprofessional Care, 19(2), 102-114.

Valaitis, R., Cleghorn, L., Ploeg, J., Risdon, C., Mangin, D., Dolovich, L., Agarwal, G., Oliver, D., Gaber, J., \& Chung, H. (2020). Disconnected relationships between primary care and community-based health and social services and system navigation for older adults: A qualitative descriptive study. BMC Family Practice, 21(69), 1-11.

Venturato, L, Horner, B \& Etherton-Beer, C (2019) Development and evaluation of an organisational culture change intervention in residential aged care facilities. Australien Journal of Ageing, 56-63. DOI: https://doi.org/10.1111/ajag.12667.

Vyt, A. (2008). Interprofessional and transdisciplinary teamwork in healthcare. Diabetes/Metabolism Research and Reviews, 24(Suppl 1), 106-109.

Wikström, E (2005), Inflytandets paradoxer: Möjligheter och hinder för självbestämmande i hemtjänsten. Paradoxes of interests: Opportunities and barriers to self-determination as a home help. Institutionen för Samhällsvetenskap, Växjö universitet (diss, lic).

Wikström, E. \& Thulesius, H, (2013) Utvärdering av en länsövergripande försöksverksamhet "Samordning för Linnea". Evaluation of a county-wide pilot scheme "coordination for Linnea". FoU Kronoberg, FoUskrift 2013:1. County council of Kronoberg.

Publisher's Note Springer Nature remains neutral with regard to jurisdictional claims in published maps and institutional affiliations. 